
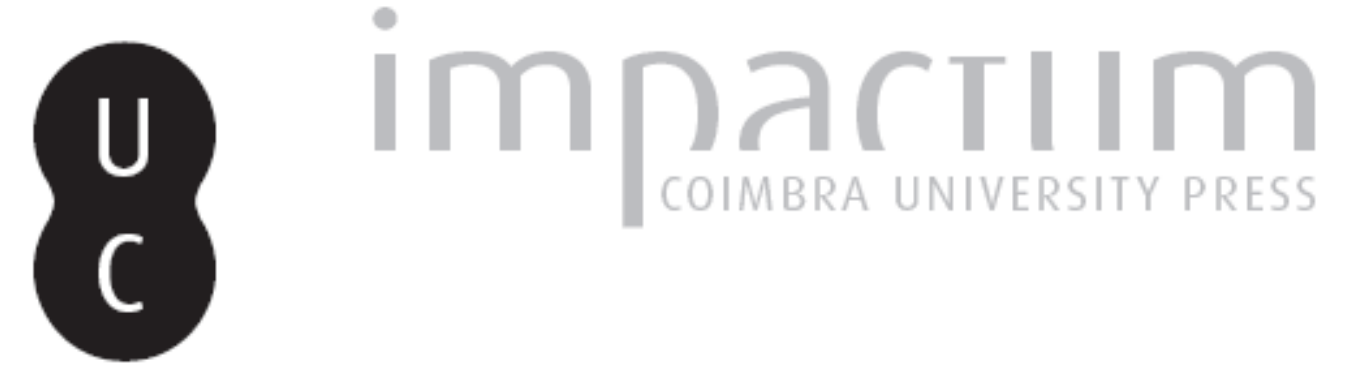

\title{
Sinais de fogo: análise antropológica de restos ósseos cremados do Neolítico final/Calcolítico do tholos OP2b (Olival da Pega, Reguengos de Monsaraz)
}
Autor(es):
Silva, Filipa Cortesão; Cunha, Eugénia; Gonçalves, Victor
Publicado por: CIAS - Centro de Investigação em Antropologia e Saúde
URL persistente:
URI:http://hdl.handle.net/10316.2/28865
DOI:
DOI:http://dx.doi.org/10.14195/2182-7982_25_7
Accessed : $\quad$ 26-Apr-2023 10:20:25

A navegação consulta e descarregamento dos títulos inseridos nas Bibliotecas Digitais UC Digitalis, UC Pombalina e UC Impactum, pressupõem a aceitação plena e sem reservas dos Termos e Condições de Uso destas Bibliotecas Digitais, disponíveis em https://digitalis.uc.pt/pt-pt/termos.

Conforme exposto nos referidos Termos e Condições de Uso, o descarregamento de títulos de acesso restrito requer uma licença válida de autorização devendo o utilizador aceder ao(s) documento(s) a partir de um endereço de IP da instituição detentora da supramencionada licença.

Ao utilizador é apenas permitido o descarregamento para uso pessoal, pelo que o emprego do(s) título(s) descarregado(s) para outro fim, designadamente comercial, carece de autorização do respetivo autor ou editor da obra.

Na medida em que todas as obras da UC Digitalis se encontram protegidas pelo Código do Direito de Autor e Direitos Conexos e demais legislação aplicável, toda a cópia, parcial ou total, deste documento, nos casos em que é legalmente admitida, deverá conter ou fazer-se acompanhar por este aviso.

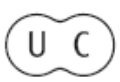




\section{Antropologia Portuguesa}

Volume $24-25 \cdot 2007-2008$

Departamento de Antropologia | Universidade de Coimbra

\section{Dossier Temático \\ CLAUDE LÉVI-STRAUSS}




\title{
Sinais de fogo: análise antropológica de restos ósseos cremados do Neolítico final/Calcolítico do tholos OP2b (Olival da Pega, Reguengos de Monsaraz)
}

\author{
Filipa Cortesão Silva', Eugénia Cunha', Victor Gonçalves ${ }^{2}$ \\ ${ }^{1}$ Departamento de Antropologia, Universidade de Coimbra, Portugal \\ ${ }^{2}$ Unidade de Arqueologia (UNIARQ), Faculdade de Letras, Lisboa, Portugal \\ filipacortesao@hotmail.com
}

Resumo Do espólio recuperado na escavação do tholos OP2b, localizado em Olival da Pega, no concelho de Reguengos de Monsaraz, e de cronologia Neolítico final/ Calcolítico, foram estudadas 5404 peças ósseas cremadas, 5365 das quais humanas, com vista a obter informações antropológicas de índole paleodemográfica, paleopatológica e tafonómica. O método utilizado consistiu na observação macroscópica recorrendo, quando necessário, à lupa.

Verificou-se que, dos 1927 elementos identificados e inventariados, 91,75\% não estavam completos e apresentavam teores de preservação muito baixos. Restos ósseos de, pelo menos, 16 indivíduos, nomeadamente, nove adultos e sete não adultos de distintos grupos etários integravam a amostra, tendo a diagnose sexual revelado quatro sujeitos do sexo feminino e dois masculinos. Foram, também, detectados indícios de patologia degenerativa, metabólica e traumática.

Diferentes graus de combustão, sobretudo peças ósseas alvo de temperaturas baixas da ordem dos $285^{\circ} \mathrm{C}$, e indivíduos cremados em diferentes fases de decomposição decorrem da interpretação dos "sinais de fogo". Já a frequência do número mínimo de indivíduos por tipo de osso indicia a prática de deposição primária.

A presente análise faculta uma série de dados que, certamente, irão contribuir para o conhecimento do perfil dos indivíduos depositados neste monumento megalítico, clarificando também alguns aspectos da Pré-história.

Palavras-chave Restos ósseos cremados; análise antropológica; sepultura colectiva; Neolítico final/Calcolítico; tholos OP2b; Portugal.

\begin{abstract}
From the remains recovered on the tholos OP2b excavation, located in Olival da Pega, in Reguengos de Monsaraz district, and Late Neolithic/Chalcolithic chronology, were studied 5404 segments of cremated bone, 5365 of these human. These bone pieces were studied in order to obtain anthropological information regarding paleodemography, paleopathology and taphonomy. The applied methods were based on a macroscopic observation and the use of a magnifying glass whenever necessary.
\end{abstract}


Among the obtained results, it is important to refer that $91.75 \%$ of the 1927 identified and documented segments were not complete and exhibited low levels of preservation. The sample includes the bone remains of 16 individuals, nine adults and seven non adults of different ages, and the sexual diagnosis identified four females and two males. Signs of degenerative, metabolic and traumatic pathology were also found. Different levels of combustion, especially bone segments burned in low temperatures of approximately $285^{\circ} \mathrm{C}$, and individuals cremated in different stages of decomposition resulted from fire signals interpretation. The minimum number of individuals per type of bone indicates a primary deposition.

This analysis provides a series of data that will certainly contribute to the knowledge of the profile of the individuals placed in this megalithic monument and the understanding of some aspects of the Prehistory.

Key words Cremated bone; anthropological analysis; collective burial; Late Neolithic/Chalcolithic; tholos OP2b; Portugal.

\section{Introdução}

O presente trabalho advém da análise antropológica de uma parcela do espólio ósseo recuperado na escavação da Anta 2 de Olival da Pega (OP2). Este monumento megalítico situa-se no Alentejo, no distrito de Évora, concelho de Reguengos de Monsaraz, num dos extremos a Nordeste da planície de Reguengos, perto da Ribeira da Pega e não muito distanciado do sopé de Monsaraz (Gonçalves, 1999).

Vítor Gonçalves iniciou a escavação de OP2 em 1990, tendo realizado novas campanhas em 1992, 1994, 1996 e 1997 (Gonçalves, 1999). Segundo este autor, os trabalhos puseram a descoberto um dólmen de corredor de $16 \mathrm{~m}$ de comprimento (OP2a) e quatro áreas funerárias posteriores anexas, designadamente, tholoi (OP2b a OP2e): uma individual, duas colectivas e uma outra cuja natureza ainda se encontra por esclarecer (Figura 1). Exceptuando o ambíguo OP2e, apelidado de micro-tholos pelas suas dimensões, e OP2c, onde se detectou um enterramento individual (o último desta necrópole), tanto OP2b como OP2d constituem tholos com indícios de sepulturas colectivas (Gonçalves, 1999). Relativamente a OP2d, tudo leva a crer ter sido violado na Pré-História não tendo sido identificado nenhum enterramento, seguramente, interpretado como tal (Gonçalves, 1999). OP2b, pelo contrário, demonstrou estar quase intacto o que, em paralelo com o espólio arqueológico e antropológico encontrados, suscita enormes expec- 
tativas face ao conhecimento que daí possa advir (Gonçalves, 1992; 1999; Gonçalves e Sousa, 2000).

Em termos sucintos OP2b representa um monumento de falsa cúpula, com uma câmara híbrida de dimensões 3,00 por 3,20 metros (longitudinal, transversal). Para além do enorme e diversificado espólio funerário, constituído por ofertas votivas e objectos de adorno pessoal, a escavação revelou duas grandes fases de utilização e sete camadas de deposições (Gonçalves, 1999). A cronologia precisa (Tabela 1), nomeadamente, três datas obtidas por ${ }^{14} \mathrm{C}$ situam-no na primeira metade do $3^{\circ}$ milénio, em anos de calendário (Gonçalves, 1999; Gonçalves e Sousa, 1997).

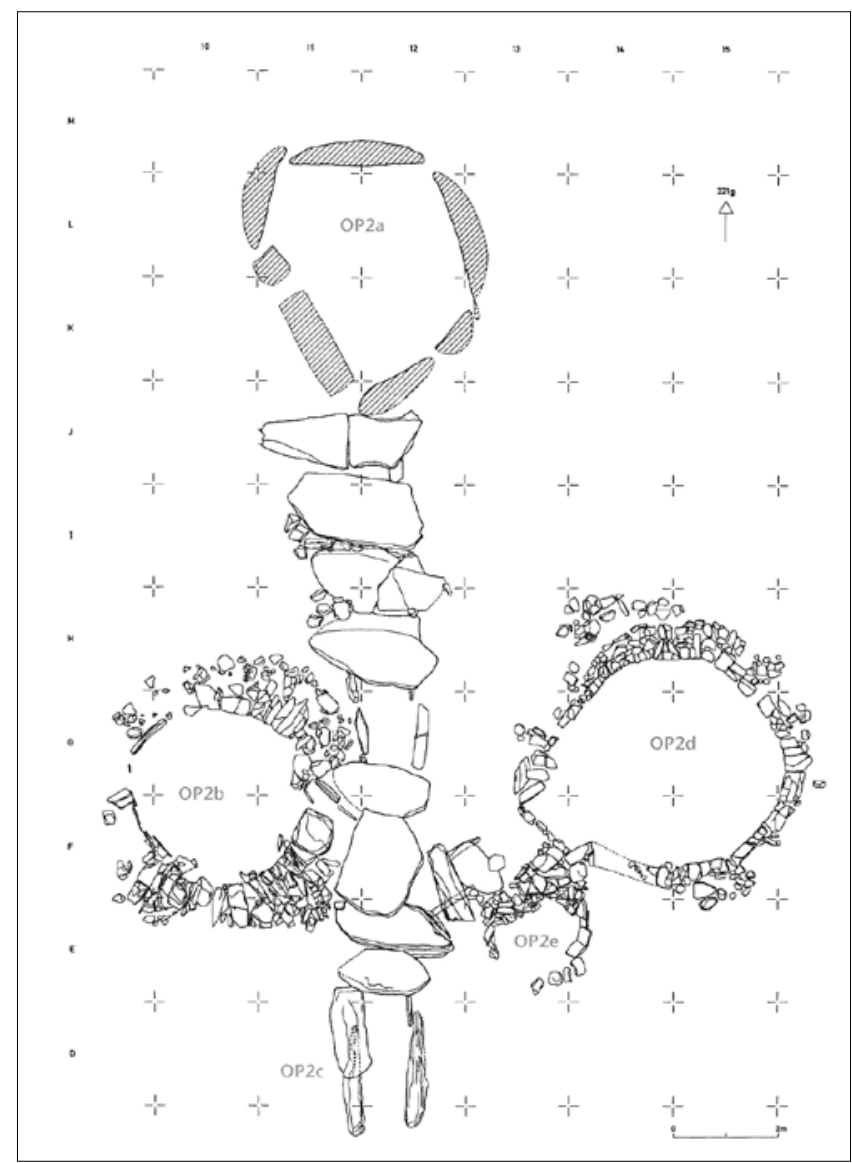

Figura 1. Planta da Anta 2 de Olival da Pega (adaptado de Gonçalves, 1999: 92). 
Tabela 1. Cronologias absolutas datadas por radiocarbono disponíveis para o tholos OP2b (adaptado de Gonçalves e Sousa, 2000: 66).

\begin{tabular}{|c|c|c|c|c|}
\hline Ref. Lab. & Amostra & Anos BP & cal a. C. 2o & Fase \\
\hline ICEN-956 & osso & $4180 \pm-80$ & $2920-2505$ & VF3 \\
\hline ICEN-955 & osso & $4290 \pm-100$ & $3303-2501$ & VF2 \\
\hline ICEN-957 & osso & $4130 \pm-60$ & $2900-2501$ & VF1 \\
\hline
\end{tabular}

Os objectivos que este trabalho se propõe cumprir estão centrados na aquisição de informações de âmbito antropológico, nas suas vertentes paleodemográfica, paleopatológica e tafonómica, em material ósseo queimado proveniente de OP2b (Olival da Pega, Reguengos de Monsaraz).

\section{Material e métodos}

O material ósseo analisado compreende o conteúdo de um dos 79 contentores plásticos de OP2b enviados para o Departamento de Antropologia (Sousa, comunicado pessoalmente em 2004). Este foi, previamente, retirado dos sacos plásticos onde estava embalado, sendo triado e identificado por regiões anatómicas por elementos do Laboratório de Paleodemografia e Paleopatologia do Departamento de Antropologia da Universidade de Coimbra.

A partir das anotações manuscritas com as coordenadas da escavação que acompanhavam os sacos plásticos, identificou-se o espólio ósseo como proveniente das quadrículas: $\mathrm{F} 10(\mathrm{Z}=150) ; \mathrm{G} 9(\mathrm{X}=189, \mathrm{Y}=060$ e $\mathrm{Z}=150)$ e $\mathrm{G} 11$ ( $\mathrm{X}=$ ?, $\mathrm{Y}=060$ e $\mathrm{Z}=153$ ). A análise destes dados e das informações da escavação indicaram que os restos ósseos pertencem ao nível designado por VF1, o que, segundo Gonçalves (1999), corresponde à primeira fase de utilização do monumento.

O estudo repartiu-se por quatro fases principais, cada uma incorporando diversas etapas para as quais foi necessário adoptar procedimentos e metodologias específicos e, simultaneamente, consentâneos com a natureza do material ósseo. A primeira fase consistiu na identificação e separação dos fragmentos ósseos. Os procedimentos detalhados para a identificação podem ser consultados em Silva (2005). Saliente-se o facto de terem surgido casos pontuais de fragmentos ósseos não humanos (falange, dente, vértebra, entre outros) e materiais de natureza diversa que foram colocados em 
distintos sacos sob as designações: não humanos, metais, cerâmica, flora e indeterminados.

Na segunda fase procedeu-se à inventariação e à anotação de características físicas patentes nos fragmentos ósseos com base em Buikstra e Ubelaker (1994). Todas as peças ósseas identificadas, por tipo de osso, foram marcadas com a sigla $\mathrm{OP} 2 \mathrm{~b}$ e respectivo número, exceptuando os minúsculos fragmentos de raízes de dentes. Concomitantemente, efectuou-se a avaliação da preservação do fragmento relativamente ao osso inteiro (caso da rótula e dos ossos do tarso e carpo) ou do segmento/sub-região óssea considerados (restantes situações). Foram atribuídos três códigos distintos: 1 (pelo menos $75 \%$ do osso presente), 2 (entre $25 \%$ a $75 \%$ do osso) e 3 (menos de $25 \%$ do osso) segundo Buisktra e Ubelaker (1994) e introduzindo algumas alterações adaptadas às condições de estudo da amostra.

Após uma observação do fragmento ósseo anotavam-se a presença ou ausência de alterações macroscópicas ao nível de textura e de morfologia. Quando estavam presentes fissuras registava-se a sua orientação (transversal ou longitudinal) relativamente ao eixo central do osso (Herrmann e Bennett, 1999) ou se estas exibiam um padrão reticulado (pátina). Como frequentemente coexistiam, num mesmo fragmento, fissuras transversais e longitudinais foram criadas subcategorias para cada uma destas duas orientações.

Para a deformação e o encolhimento era indicado se estavam patentes no fragmento. Uma vez que vários estudos demonstraram haver uma estreita associação entre encolhimento e coloração, este dado serviu igualmente de critério para inferir a ocorrência de encolhimento (Rubini e Andreini, 1990). Para além destes aspectos, fruto da acção da temperatura sobre o osso, também foram perscrutados indícios de outras alterações tafonómicas e/ou de âmbito patológico, bem como assinalada a presença de caracteres discretos.

A análise paleodemográfica compreendeu o cálculo do número mínimo de indivíduos com base em Ubelaker (1974) e Herrmann et al. (1990). Para a diagnose sexual seguiram-se as recomendações de Ferembach et al. (1977-1979), Bass (1995) e Phenice (1969), tendo sido utilizados métodos métricos, designadamente, Wahl (1996) e Wahl e Graw (2001) onde se empregou uma craveira de precisão $0.1 \mathrm{~mm}$.

A estimativa da idade à morte dos fragmentos ósseos de indivíduos adultos apoiou-se nos métodos de Brooks e Suchey (1990) e de Lovejoy et al. (1985). O elevado teor de fragmentação dos ossos cranianos impediu 
a aplicação do método de Masset (1982) ainda que, para fragmentos com sutura, se tenha observado o seu grau de obliteração. Alterações degenerativas do esqueleto serviram, igualmente, para fundamentar estimativas da idade à morte. Para os não adultos adoptaram-se as recomendações de Ferembach et al. (1977-1979). O grau de fragmentação associado à hipótese de encolhimento ósseo impediu o recurso a métodos métricos, excepto num astrágalo (Alduc-Le Bagousse, 1988) e numa tíbia (Stloukal e Hanáková, 1978 in Ferembach et al., 1977-1979). Recorreu-se, também, à comparação de fragmentos ósseos com ossos intactos de não adultos moçarabes de Serpa (Ferreira, 2000) e da Colecção de Esqueletos Identificados do Museu Antropológico da Universidade de Coimbra.

$\mathrm{Na}$ derradeira fase do trabalho foram investigadas as alterações e/ou as variações morfológicas e, em termos globais, a paleopatologia. Face à fragmentação e à mistura dos restos ósseos de vários indivíduos apenas se empregaram as escalas de Crubézy (1988) para quantificar o grau de artrose e de entesopatias. Os restantes indícios de patologias foram observados à lupa e/ou por exames radiográficos. Estes últimos tiveram lugar na sala de Mamografia do Serviço de Imagiologia dos Hospitais da Universidade de Coimbra com recurso ao seguinte equipamento: Mamógrafo General Electric, modelo Senographe DMR. Para as variações morfológicas designadas por caracteres discretos consultaram-se Saunders (1978) e Hauser e De Stefano (1989).

Concluído o estudo prático da amostra procedeu-se à informatização e ao tratamento estatístico dos dados obtidos no programa SPSS para Windows (versão 11.0, 2000), sendo também utilizado o sistema operativo Windows XP, nomeadamente a folha de cálculo do Microsoft Excel (2002).

\section{Resultados}

Num total de 5425 elementos observados, apenas $21(0,39 \%)$ revelaram não ser de natureza óssea. Inserem-se neste grupo uma raiz de origem vegetal; 17 fragmentos minerais/pedra e três de cerâmica. Em relação ao conjunto constituído pelas peças ósseas e dentes, este integra 5404 elementos, dos quais 39 não são humanos.

Os restantes elementos ósseos e dentários humanos ( $\mathrm{N}=5365)$ estão, genericamente, repartidos por duas grandes categorias: não identificados ( $\mathrm{N}=3320)$ e aqueles em que foi viável um nível mínimo de identificação ( $\mathrm{N}=2045$ ). A amostra integra, portanto, 1927 peças ósseas e 118 dentárias, 
o que corresponde a 38,12\% dos elementos humanos observados. Em termos globais, as percentagens relativas à identificação dos 1927 elementos ósseos em função da região anatómica revelaram: cranium 25,69\%; membros superiores $20,34 \%$; tórax e vértebras $31,71 \%$ e membros inferiores $22,26 \%{ }^{1}$.

Dos 1927 elementos ósseos inventariados somente $159(8,25 \%)$ estão completos. Tal valor revela um grau de fragmentação de 91,75\%. Já a avaliação da preservação do fragmento por osso, de acordo com os três graus propostos por Buikstra e Ubelaker (1994), indica que o carpo detém a maior percentagem de elementos ósseos com grau 1 (87,10\%), seguindo-se as falanges do pé $(74,47 \%)$ e das mãos $(56,19 \%)$. Já as costelas, cranium e coxal ostentam, para este grau, os valores mais baixos com, respectivamente, $1,58 \%, 2,02 \%$ e $7,58 \%$.

Se, em contrapartida, forem observadas as percentagens de fragmentos com grau 3 (por osso ou grupo de ossos) percebe-se que o cenário se inverte. Exceptuando os $96 \%$ da omoplata, os valores mais elevados residem no cranium (92,53\%), nas costelas $(91,46 \%)$ e no coxal $(83,33 \%)$. Quanto aos resultados visando o grau intermédio de preservação indicam que os metacárpicos são os detentores da maior percentagem (60\%), seguindo-se a clavícula $(50 \%)$ e a rótula $(46,15 \%)$.

\section{Análise tafonómica}

Para a análise da acção do fogo foram pesquisadas quatro categorias de características físicas: coloração, deformação, encolhimento e fragmentação.

Ao nível da coloração os resultados revelaram 61,44\% $(\mathrm{n}=1184)$ elementos ósseos amarelos, 3,17\% $(\mathrm{n}=61)$ castanhos, $0,16 \%(\mathrm{n}=3)$ pretos, $16,40 \%(\mathrm{n}=316)$ cinza, $16,97 \%(\mathrm{n}=327)$ brancos e $1,87 \%(\mathrm{n}=36)$ com coloração mista ${ }^{2}$. Dentro das colorações amarela, cinzenta e branca observaram-se associações com outras cores. As nuances cromáticas mais frequentemente associadas ao amarelo, cinzento e branco foram, respectivamente, o laranja, o branco e o cinza ou azul ${ }^{3}$. Para os casos de coloração

${ }^{1}$ Para mais detalhes relativos às peças ósseas identificadas consulte-se Silva (2005).

${ }^{2}$ A coloração mista diz respeito aos casos onde não foi possível definir uma coloração predominante pelo facto da peça óssea exibir colorações distintas consoante a norma em que é observada.

${ }^{3}$ Em Silva (2005) podem ser visualizadas diversas figuras ilustrativas das distintas colorações. 
mista $(\mathrm{n}=36)$ foram criadas várias subcategorias de acordo com as duas cores principais: amarelo/cinza $(11,11 \%)$, cinza/castanho $(55,56 \%)$ e castanho/preto $(8,33 \%)$.

No que se refere à deformação, esta encontra-se patente em 7,78\% (n= $150)$ das peças ósseas. Quanto ao encolhimento, 20,65\% $(\mathrm{n}=398)$ manifesta fortes indícios de ter sido alvo deste fenómeno. Se, todavia, forem considerados os casos mais ambíguos, onde a possibilidade de encolhimento é equacionada $(15,98 \% ; n=308)$, a percentagem já se situa nos 36,63\% $(n=706)$.

Com fragmentação foram observados $38,56 \%(\mathrm{n}=743)$ elementos ósseos, nomeadamente: fissuras longitudinais $(8,46 \% ; \mathrm{n}=163)$, transversais $(8,56 \% ; \mathrm{n}=165)$, laminação $(0,10 \% ; \mathrm{n}=2)$, pátina $(17,54 \% ; \mathrm{n}=$ $338)$ e textura mista ${ }^{4}(3,89 \% ; n=75)$. Dentro desta última subcategoria importa referir que 64\% $(n=48)$ dos elementos ósseos possuem fissuras longitudinais e pátina, enquanto que os restantes $36 \%(\mathrm{n}=27)$ apresentam fissuras transversais e pátina. Tanto as fissuras longitudinais como as transversais foram alvo de uma divisão em subcategorias. Dentro das primeiras registaram-se 125 casos de fissuras longitudinais simples (76,69\%), 22 de oblíquas (13,50\%), 14 de longitudinais com transversais $(8,59 \%)$ e 2 casos de fissuras radiadas $(1,23 \%)^{5}$. Fissuras transversais encurvadas $(\mathrm{n}=141)$ (Figura 2) e fissuras transversais com longitudinais $(n=24)$ integram, por sua vez, as duas subcategorias de fissuras transversais detectadas, evidenciando percentagens de, respectivamente, $85,45 \%$ e $14,55 \%$.
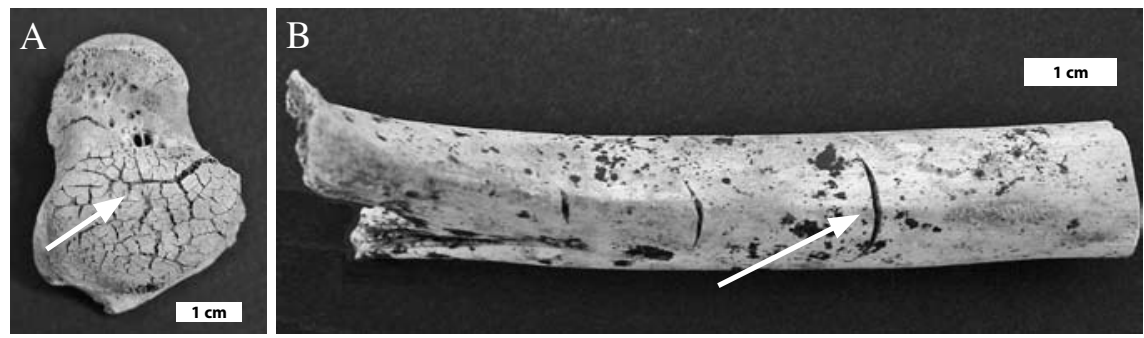

Figura 2. Astrágalo direito (OP2b 593) em norma superior com pátina (A) e fragmento de úmero esquerdo (OP2b 120) em norma lateral, exibindo fissuras transversais encurvadas (B).

${ }^{4}$ A textura mista diz respeito aos casos onde, na mesma peça óssea, se assinalaram, simultaneamente, fissuras longitudinais ou transversais e pátina.

5 Tanto as fissuras "longitudinais com transversais" como as fissuras "radiadas" são designações criadas por Silva (2005) por não se enquadrarem nos dois tipos de fissuras longitudinais descritas na bibliografia. 
A amostra apresenta 695 (36,07\%) elementos ósseos com alterações tafonómicas não atribuíveis ao fogo, sendo os mais afectados os metacárpicos $(74 \%)$ e os ossos do carpo $(70,97 \%)$, enquanto que os valores mais baixos se situam no esterno e nas falanges do pé com, respectivamente, $16,67 \%$ e $19,15 \%$.

As distintas alterações tafonómicas observadas dizem respeito, lato sensu, a pintas pretas e a manchas verdes, orifícios e outras variações, como sejam: fracturas recentes, bolores e/ou pequenas excrescências de natureza indeterminada. $\mathrm{O}$ peso de cada um destes sinais no conjunto de elementos ósseos alterados reparte-se do seguinte modo: pintas pretas $82,88 \%$ ( $\mathrm{n}=$ $576)$, manchas verdes $8,63 \%(n=60)$, orifícios $6,04 \%(n=42)$ e outras alterações $8,63 \%(n=60)$.

\section{Análise paleodemográfica e de variações morfológicas}

Constata-se existirem, pelo menos, nove indivíduos adultos, facto revelado pelo terço médio da diáfise do rádio esquerdo (Silva, 2005). Já a determinação do número mínimo de não adultos sugere a presença de sete indivíduos (43,75\%), cinco obtidos a partr da tíbia e ajustados de novo devido à presença inequívoca de, pelo menos, um indivíduo com idade inferior aos 2 anos de idade e à existência de dois indivíduos de idades semelhantes (cerca de 6 anos \pm 12 meses) detectada ao nível de dois primeiros metacárpicos direitos. Assim, no total, é razoável pressupor que a amostra do presente trabalho contemple, pelo menos, 16 indivíduos, $56,25 \%$ (9) dos quais adultos e $43,75 \%$ (7) jovens.

Não obstante as limitações impostas pela natureza do material, foram estimados parâmetros demográficos como a idade à morte, o sexo e os caracteres discretos. A análise detalhada dos dados obtidos indicou que os sete indivíduos não adultos estão distribuídos por todos os grupos etários considerados (Figura 3). Por questões metodológicas optou-se por circunscrever à categoria de não adultos somente os indivíduos com idades inferiores aos 15 anos inclusive. 


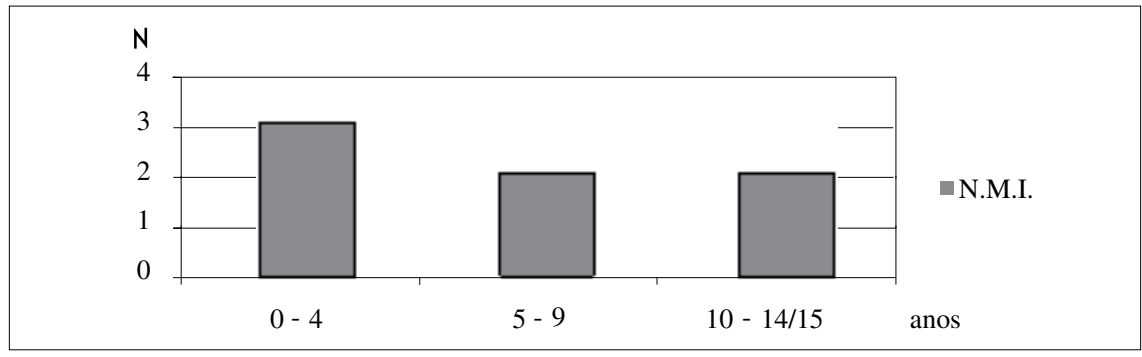

Figura 3. Número de mínimo de indivíduos (N. M. I.) não adultos por grupo etário.

Quanto aos adultos, apenas os casos a seguir expostos viabilizaram estimativas da idade à morte minimamente credíveis. Argumentos claros sustentam a presença de, pelo menos, dois adultos jovens identificados pela extremidade medial de uma clavícula (OP2b 840) e por dois fragmentos de corpos de vértebras torácicas (OP2b 1239 e OP2b 1246) mediante análise dos sinais de união das respectivas epífises. As estimativas alcançadas, a partir da inspecção da morfologia da sínfise púbica (Brooks e Suchey, 1990), dão conta de dois indivíduos de sexo indeterminado pertencentes ao grupo etário dos 15 aos 23/24 anos, de uma mulher com 26 a 70 anos, de dois indivíduos de sexo indeterminado com idades superiores ou iguais aos 23 ou 26 (para indivíduos do sexo masculino e feminino, respectivamente) e de um indivíduo do sexo masculino com idade entre os 34 a 86 anos; enquanto que a observação da superfície auricular (Lovejoy et al., 1985) revela a presença de dois indivíduos com 30 a 34 anos e de um indivíduo pertencente ao grupo etário dos 40 a 44 anos. Os resultados sugerem então um mínimo de três indivíduos pertencentes a grupos etários distintos. Acrescente-se ainda que a apreciação do grau de obliteração das suturas em 77 fragmentos cranianos aponta para adultos não muito velhos, uma vez que em quase todos $(83,12 \% ; n=64)$ as suturas se encontravam abertas. Outro dos parâmetros perscrutados foi a patologia degenerativa que continua a indicar adultos com idades pouco avançadas, tanto pela reduzida incidência de casos como pelo diminuto grau de artrose evidenciado. Em suma, com base nas informações disponíveis afigura-se mais correcto, e prudente, concluir que na amostra há dois adultos jovens, um adulto e um adulto idoso.

A diagnose sexual com base na metodologia de Ferembach et al. (19771979) revelou peças ósseas cranianas, na sua maioria, de indivíduos do sexo feminino, designadamente: frontal (sete femininas versus três masculinas; 
zigomático (três esquerdas masculinas, duas femininas e uma masculina direitas) e mandíbula/menton (duas masculinas). Saliente-se que os valores apresentados incluem os casos feminino (?) e masculino (?).

Da aplicação do método de Phenice (1969), somente viável em duas situações, resultaram indivíduos de sexos diferentes. Quanto à percepção da robustez das peças ósseas, sugere a presença de mais do que um indivíduo do sexo feminino e de, pelo menos, um masculino. Tal suposição encontra-se espelhada em ossos como o rádio, o cúbito e os côndilos mandibulares.

Um pouco mais concretos foram os dados alcançados a partir da aplicação do método de Wahl e Graw (2001). Atendendo aos valores auferidos para oito pirâmides petroseais (Silva, 2005) é de considerar a presença de quatro elementos femininos e dois masculinos.

Os valores decorrentes da medição da espessura da diáfise do úmero e do rádio (critérios 3c e 4 de Gejvall, 1963 in Wahl, 1996) e posterior comparação com as informações prestadas por Wahl (1996), demonstraram-se pouco úteis na diagnose sexual, uma vez que, na maioria dos casos, se situam no intervalo onde as peças ósseas tanto podem ter pertencido a indivíduos do sexo masculino como feminino. Estes dados, respeitando medições a 16 fragmentos, encontram-se disponíveis em Silva (2005).

Ao nível dos caracteres discretos importa ressaltar que a fragmentação e o fraco grau de preservação das peças ósseas podem ter mascarado evidências desta natureza. Todavia, foram pesquisados: sutura metópica, chanfradura supraorbitária, foramen supraorbitário, foramina zigomaticofacial, torus palatino, torus mandibularis, foramina mentalia duplo, abertura septal, fossa rombóide, perfuração supraclavicular, patella emarginate, faceta intrusa média da tíbia e faceta intrusa lateral da tíbia. Desta lista apenas se observaram dois casos $(18,18 \%, 2 / 11)$ de chanfradura supraorbitária (OP2b 1458 e OP2b 1459), um caso $(25 \%, 1 / 4)$ de sutura metópica e/ou supranasal (OP2b 1463) e uma $(25 \%, 1 / 4)$ situação de perfuração supraclavicular (OP2b 833).

\section{Análise paleopatológica}

As informações a seguir apresentadas devem ser encaradas com as devidas reservas, uma vez que provêm de um contexto de mistura dos restos ósseos de diversos indivíduos onde imperam a fragmentação e uma reduzida preservação. 
No total foram detectados 34 elementos ósseos com indícios de artrose $(82,35 \%)$ aos quais, na maioria das vezes, foi atribuído o grau 1 , de acordo com a classificação de Crubézy (1988), sendo as peças mais afectadas o cúbito $(\mathrm{n}=5)$ e as vértebras $(\mathrm{n}=12)$. Os restantes casos encontram-se distribuídos pelos ossos da mão $(n=8)$, do pé $(n=4)$, da rótula $(n=3)$, do rádio $(\mathrm{n}=1)$ e do perónio $(\mathrm{n}=1)$.

Quanto às entesopatias documentaram-se 44 casos, os quais contemplam 13 tipos de lesões. As lesões mais frequentes localizam-se no bíceps brachii, no ligamento rotuliano e no ligamento flexor das falanges proximais. Quase todas as lesões são de grau 1. Os casos de grau 2 incidem sobretudo nos ligamentos flexores das falanges enquanto a única situação de grau 3 concerne uma lesão entesopática visível numa rótula (Figura 4). A incidência das distintas entesopatias por lateralidade das peças ósseas revelou resultados bastante homogéneos na frequência das distintas lesões e na severidade com que estas se manifestaram.

Figura 4.

Entesopatia detectada numa rótula direita (OP2b 473), em norma anterior.

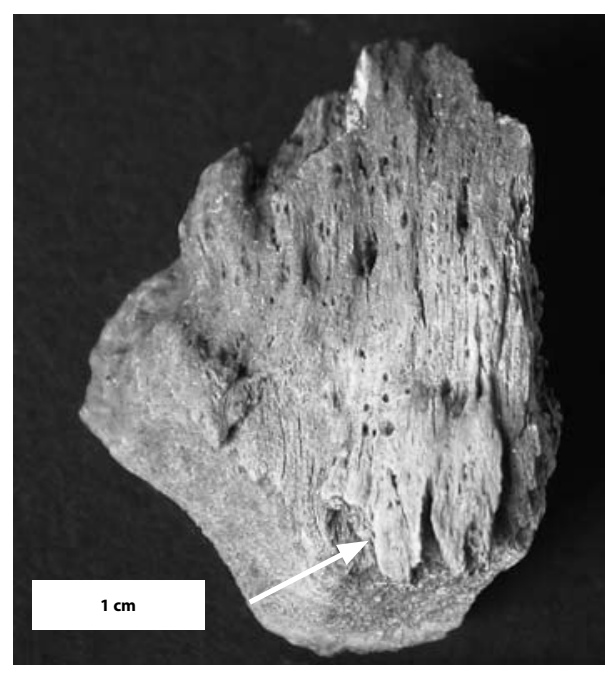

No que se refere a outros indícios de patologia, foram detectados cinco fragmentos cranianos (OP2b 1515, 1520, 1518, 1519 e 1522) ostentando grande espessura do diploe, entre 5 e $8 \mathrm{~mm}$, os quais, hipoteticamente, terão pertencido ao mesmo indivíduo.

Para as peças ósseas dos membros superiores há a assinalar três situações distintas. Uma diz respeito a um presumível caso de osteocondritis dissecans na 
cabeça de um rádio direito (OP2b 136) (Figura 5). A lesão em causa tem 6,53 $\mathrm{mm}$ e $5,81 \mathrm{~mm}$, respectivamente de diâmetros transverso e longitudinal. Este osso exibe ainda macroporosidade junto à tuberosidade radial acompanhada de entesopatia. Outra das situações registadas prende-se com a suspeita de uma fractura num $3^{\circ}$ metacárpico esquerdo (OP2b 289). Macroscopicamente, é visível um calo ósseo ao meio da diáfise cuja interpretação da radiografia, efectuada em norma lateral, confirma a origem traumática e sugere tratar-se de uma fractura transversal. Ainda nos membros superiores, num escafóide (OP2b 251) e num capitato (OP2b 256) esquerdos observam-se pequenos orifícios de forma circular e de contorno regular situados fora das zonas articulares.
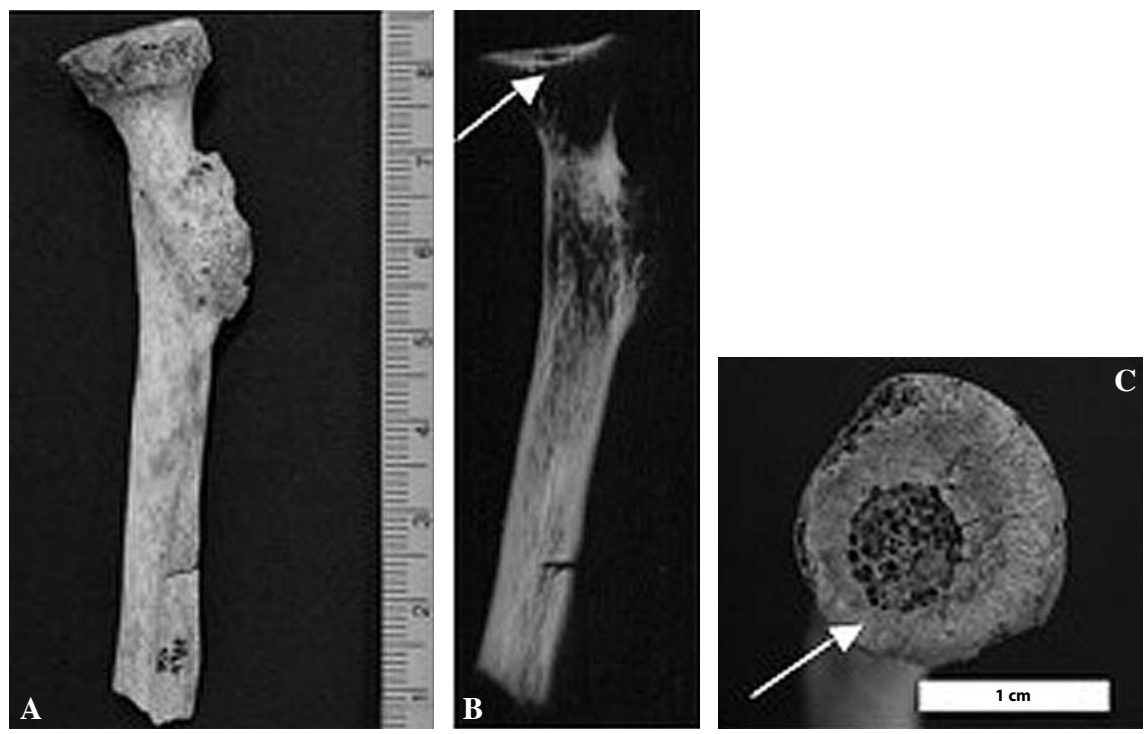

Figura 5. Rádio direito de um indivíduo adulto (OP2b 136) (A) e respectiva radiografia (voltagem: $31 \mathrm{KV}$; exposição: $16 \mathrm{mAs}$; distância objecto - imagem: $660 \mathrm{~mm}$ ) em norma anterior (B), exibindo na cabeça uma lesão compatível com osteocondritis dissecans (C em norma superior).

Relativamente aos sinais de patologia óssea do tórax e da coluna vertebral foram identificados: um caso de spina bifida (Figura 6) percepcionado na metade direita de um atlas (OP2b 1173), um nódulo de Schmorl numa vértebra lombar (OP2b 1291), assim como modificações na superfície visceral, nomeadamente espessamento ântero-posterior em dois fragmentos de costela (OP2b 921 e OP2b 922). 
Figura 6.

Provável caso de spina bífida atlantis. Atlas (OP2b 1173) em norma superior.

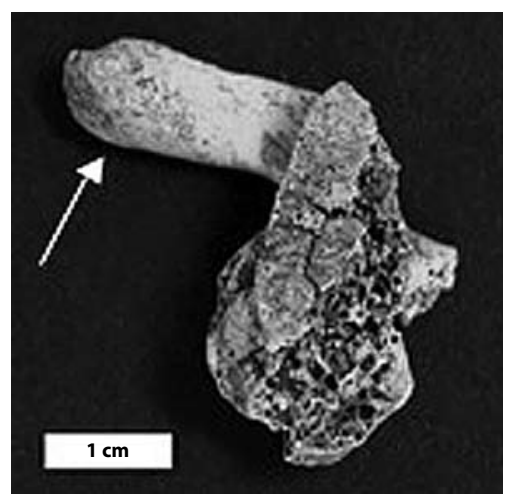

Por fim, nas peças ósseas dos membros inferiores foram registados, num perónio direito (OP2b 575), uma espícula na extremidade distal, e osso novo, do tipo woven, no epicôndilo medial dum fémur direito (OP2b 448).

\section{Discussão e conclusões}

\section{Identificação, representatividade e grau de preservação por tipo de osso}

A percentagem de fragmentos ósseos humanos não identificados na amostra do tholos OP2b insere-se na estimativa de McKinley e Bond (2001) onde, por norma, num rito funerário de cremação, somente 30 a $50 \%$ dos restos ósseos são susceptíveis de ser identificados com um elemento específico do esqueleto. Para Spence (1967) cerca de metade do material de uma cremação visa fragmentos de ossos longos não identificados, enquanto Mays (1998) declara a existência, na maioria das cremações, de uma parte substancial de osso cuja identificação com um elemento do esqueleto, ou até mesmo com categorias mais amplas é inexequível.

Quanto às diferenças patentes nos níveis de identificação das peças, por tipo de osso, devem-se a vários factores. Dois dos basilares respeitam especificidades morfológicas ou estruturais da peça (Grévin et al., 1998) e respectivo grau de preservação, o que leva, tal como Mays (1998) salienta, a que peças de algumas partes do esqueleto sejam mais fáceis de identificar do que outras. 
Circunscrevendo a análise ao conjunto das peças onde houve o reconhecimento do osso, do segmento ou da sub-região óssea, bem como da lateralidade (no caso dos ossos pares) e da idade (adulto/não adulto) acede-se a dados no campo da Paleodemografia e da Antropologia Funerária. Esta estratégia tem sido adoptada, por Gatto e Buquet (2000), Gatto et al. (2003), Chambon (1999) ou Silva (2002), em estudos de sepulturas colectivas, para calcular a frequência do número mínimo de indivíduos (N.M.I.) por tipo de osso, obtendo assim o "perfil osteológico" da sepultura (Chambon, 1999; Gatto e Buquet, 2000). Outra das informações extrapoladas visa o conhecimento do tipo de deposição (primário, secundário, ou se, pelo contrário, a sepultura foi alvo de esvaziamento) a que terão sido submetidos os restos humanos (Chambon, 1999).

Dado que o presente estudo contempla parte do material ósseo recuperado em OP2b pode avançar-se que o "perfil osteológico" alcançado dá credibilidade à hipótese dos restos ósseos observados resultarem de deposição primária. A sustentar esta convicção encontra-se, por um lado, a homogeneidade detectada nas frequências de N.M.I. entre os distintos ossos e, por outro, como registaram Gatto e Buquet (2000) ou Gatto et al. (2003), os altos valores de ossos de pequenas dimensões, como sejam os do carpo e do tarso, bem como de metatársicos e de metacárpicos, relativamente à frequência máxima de N.M.I. da amostra.

Face à fragmentação existente, tudo leva a crer que o manuseamento dos restos ósseos possa constituir um dos grandes responsáveis por este fenómeno. Outro dos principais agentes obreiros da fragmentação percepcionada foi o fogo. Discernir qual a responsabilidade de cada um deles é impraticável, ainda que se deva estar inteirado que, ao contrário do que se poderá supor, o fogo pode não ser o principal agente da fragmentação, como o corroboram as conclusões do estudo realizado por McKinley (1994) ou a grande fragmentação em material ósseo não cremado de sepulturas colectivas (Toussaint, 1991; Silva, 2002).

Não obstante esta realidade, sabe-se que a fragmentação integra o rol de características físicas, apanágio de restos ósseos cremados, devido às alterações desencadeadas nos constituintes ósseos (Silva, 2007). Através de experiências efectuadas por Stiner e co-autores (1995) ficou, igualmente, demonstrado que a acção do fogo aumenta a susceptibilidade para a fragmentação óssea. Dado que 35,39\% das peças ósseas apresenta coloração 
entre o preto e o branco é muito provável que o fogo tenha exercido forte influência na fragmentação experimentada, sobretudo nos ossos longos.

Na amostra estudada, os parcos casos a escapar incólumes à fragmentação têm em comum o facto de serem, quase exclusivamente, ossos pequenos e de formato esférico. A explicação mais plausível para este fenómeno é que tais características têm reflexos nas propriedades mecânicas permitindo que estes possam ser alvo de forte compressão e de outras forças sem experimentarem deformação ou fractura (Darwent e Lyman, 2002). Já peças ocas (tais como o crânio), sólidas ou cilíndricas (caso dos ossos longos), achatadas (como seja a omoplata) não conseguem suportar forças de magnitude similar (Currey, 1984 in Darwent e Lyman, 2002).

Apesar do tamanho e da forma dos ossos serem aspectos importantes na argumentação referente à fragmentação e à preservação óssea observada, há que realçar sobretudo o papel desempenhado pela densidade óssea. Galloway et al. (1997) consideram inclusive que, de todas as variáveis intrínsecas, esta possa ser a que individualmente mais influencia a preservação.

Direccionando agora o olhar para os níveis de preservação dos elementos ósseos da amostra constata-se, a priori, que os dados alcançados são similares aos de Blau (2001a), nomeadamente, que a maioria, mais de 60\%, exibe grau 3, ou seja, menos de $75 \%$ do osso presente. Em certa medida, alguns dos níveis de preservação por tipo de osso, do presente trabalho, poderse-ão justificar recorrendo ao argumento da densidade óssea. Ossos pouco densos como sejam as vértebras, as costelas, o esterno (Boddington, 1987; Nawrocki, 1995 in Stojanowski et al., 2002), ou a omoplata (Stojanowski et al., 2002) registaram níveis de preservação muito baixos, representando, por isso, confirmações à regra, sendo as excepções os ossos do carpo e do tarso detentores de valores elevados de preservação não obstante a sua parca densidade.

Verifica-se, de igual modo, que a preservação exibida por certas subregiões ósseas densas (caso da pirâmide petroseal) ou pelos segmentos de diáfise dos ossos longos é susceptível de ser interpretada como sendo fruto da associação entre preservação e densidade. A apoiar esta suposição encontram-se as informações disponibilizadas por Waldron (1987) sobre a pirâmide petroseal e os dados fornecidos por Stojanowski et al. (2002) relativamente aos ossos longos.

Após a discussão dos resultados visando a identificação, representatividade e o teor de preservação dos elementos ósseos que integram a 
amostra deste estudo percebe-se que a interpretação dos valores obtidos em cada um destes itens tem de ser feita em conjunto por estarem estritamente interligados (Figura 7).

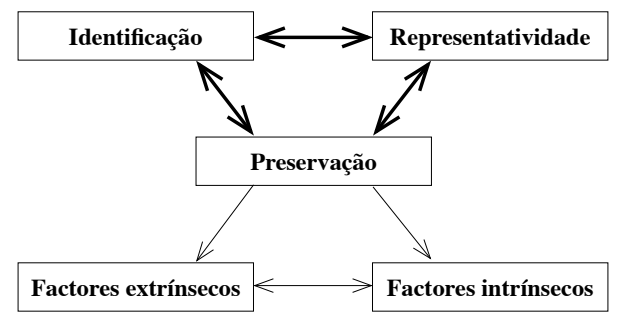

Figura 7. Relação entre identificação, representatividade e preservação na amostra estudada (setas a cheio indicam a ligação entre estes três itens enquanto que as restantes sinalizam os factores envolvidos na preservação).

A associação entre os itens identificação e representatividade advém do facto de o primeiro determinar inevitavelmente o perfil exibido pelo segundo. Quanto menos precisa for a identificação, mais distanciados da realidade serão os valores da representatividade óssea. A identificação e, consequentemente, a representatividade dependem, de igual modo, da preservação óssea, a qual, por sua vez, é fruto da interacção de factores extrínsecos e intrínsecos ao próprio osso.

Conhecidas por pseudopatologias, as alterações ósseas post mortem resultam de dois factores básicos, concretamente, o ambiente de enterramento circundante e de problemas durante, ou após, a escavação (Ortner, 2003). No que concerne ao fogo, e de acordo com a proposta de categorização do grau de combustão elaborada por Stiner et al. (1995), mais de metade das peças ósseas da amostra não terá sido alvo deste agente visto exibir a coloração amarela. Se, todavia, for tido em linha de conta Heglar (1984), tal coloração significa apenas que as peças ósseas estiveram ligeiramente expostas a baixas temperaturas. Uma terceira hipótese explicativa, talvez a mais plausível, é que entre as peças ósseas amarelas coexistam os dois cenários. No mínimo, poder-se-á afirmar, sem reservas, que as peças ósseas amarelas com nuances cinza ou laranja (Mays, 1998) ou as que ostentam fissuras transversais (Herrmann e Bennett, 1999) ilustram casos de exposição ao calor. O reduzido número de elementos ósseos castanhos e pretos ou com as cores castanho/cinza ou castanho/preto reflecte, grosso modo, 
temperaturas pouco elevadas sendo o preto sinónimo de osso carbonizado (Pajot, 1986; Etxeberria, 1994). Já as colorações cinza e branca, patentes em pouco mais de um quarto da amostra e com uma distribuição muito semelhante entre si, traduzem temperaturas elevadas, especialmente a segunda, que revela de acordo com Correia (1997) ossos calcinados. Ainda que as distintas colorações observadas possam denunciar a exposição dos restos ósseos da amostra a diferentes temperaturas, estas são, de igual modo, fruto de variáveis como o tempo de exposição, a localização da combustão (Heglar, 1984) e a distância ao foco de calor (Botella et al., 2000). Para Botella et al. (2000) a presença de diversas cores numa mesma peça óssea é, justamente, consequência de uma exposição ao calor mais directa e pontual de umas zonas em relação a outras. $\mathrm{Na}$ amostra, as peças ósseas de coloração mista constituem um exemplo particularmente evidente desta circunstância.

É de notar que, muito embora tenha sido interpretada como produto da acção do fogo, a cor vermelha detectada nalgumas peças ósseas pode, igualmente, ser fruto do ocre. De acordo com Silva $(1996,2002)$ e Gonçalves (1999) confirma-se a sua presença em várias sepulturas pré-históricas portuguesas. Todavia, na presente amostra, não foram observadas evidências suficientemente claras para que esta hipótese seja fundamentada.

No presente trabalho apenas $35,39 \%$ das peças ósseas exibem marcas inequívocas de combustão, o que, comparativamente com Blau (2001b), está muito aquém dos $90,7 \%$ detectados em Unar 2 (Península Oman; cronologia situada no $3^{\circ}$ milénio a.C. ${ }^{6}$ ). Igualmente discrepantes são os valores relativos à coloração branca: 70,1\% (Blau, 2001b) contra os 16,97\% da amostra. Um pouco mais próximos da presente amostra são os $56 \%$ encontrados por Idánez (1986 in Benito, 2002) nos restos humanos do sepulcro megalítico de Murviedro (Múrcia) ou os 53,5\% exibidos pelos elementos ósseos da sepultura I de al-Sufuh (Dubai) datada entre 2400 a 2300 a. C. (Blau, 2001a). Gonçalves (1992) menciona a recolha, por parte dos Leisner, de ossos carbonizados em Antas do Concelho de Reguengos de Monsaraz, nomeadamente, Passo 1, Comenda 2, OP1 e Cebolinhos. Seria interessante em estudos futuros comparar o teor da acção do fogo no espólio ósseo destes monumentos.

Relativamente ao encolhimento ósseo, e atendendo aos critérios utilizados para inferir a sua existência na amostra, não será, de estranhar que os resultados espelhem os valores auferidos para as colorações cinza e branca.

${ }^{6}$ Entre 2300 a 2100 a. C., segundo Velde et al. (comunicação pessoal in Blau, 2001b). 
Sobre este ponto apenas se pode afirmar que, em algumas das peças ósseas alvo de encolhimento ósseo, este fenómeno se apresenta bastante evidente, denunciando, assim, as alterações ósseas descritas em Silva (2007).

Já a interpretação dos dados ao nível da deformação indica que os elementos por ela afectados seriam ossos frescos aquando da combustão (Baby, 1954 in Thurman e Willmore, 1980-1981; Binford, 1972 in Thurman e Willmore, 1980-1981; Eckert et al., 1988). As diferenças encontradas nos valores de deformação, por tipo de osso, reproduzem o ponto de vista de Depierre (1995), nomeadamente, a ligação entre deformação e as distintas proporções de matéria compacta e esponjosa nos ossos longos, nos chatos e nos curtos. $\mathrm{O}$ facto dos ossos longos serem os que mais experimentaram deformação explica-se pela diminuta elasticidade do tecido compacto (Depierre, 1995). Porém, não foi possível comparar os valores da deformação óssea do presente trabalho com a de outros estudos referidos na bibliografia por nenhum abordar este parâmetro em moldes afins.

Em termos de extrapolações acerca das fissuras detectadas impõe-se, desde logo, alertar para o impacto negativo que o grau de fragmentação/ preservação possa ter exercido na recolha e na interpretação destes dados. As fissuras transversais encurvadas detectadas em ossos longos são produto de uma combustão envolvendo carne/tecidos moles (Herrmann e Bennett, 1999; Symes et al., 2001). Contrariamente aos resultados obtidos por Gatto e Buquet (2000) ou os de Chambon (1999), a presente amostra também incorpora peças de ossos longos com fissuras longitudinais. Estas são características de ossos secos queimados (Guillon, 1987; Ubelaker, 1989; Etxeberria, 1994), pelo que é de admitir, à semelhança do que foi sugerido por Vázquez et al. (2002), a possibilidade de vestígios humanos num estado de esqueletização avançado ou mesmo completo, também terem sido alvo de combustão. Face à presença destes dois tipos de fissuras na amostra, presumese, tal como Masset (2002) sugere, que aquando da combustão coexistissem no mesmo espaço indivíduos em diferentes estádios de decomposição.

Por ora, o estado da arte na análise de restos ósseos cremados não viabiliza a discussão dos valores relativos às fissuras pátina e mista. Relativamente às primeiras, pode apenas referir-se que se manifestaram em zonas onde predomina o tecido esponjoso, nomeadamente, nas extremidades proximal e distal de ossos longos e curtos, nas cavidades glenóide e acetabular, nas facetas articulares das costelas e das vértebras, em ossos do carpo e do tarso e em ossos cranianos. 
No que se refere às associações vigentes entre coloração, deformação, encolhimento e fragmentação, os valores indicam, como seria de esperar, que o grau de combustão, inferido através da coloração, é determinante no encolhimento experimentado, assim como também parece influenciar a ocorrência de deformação. Menos óbvia, ou mais fraca, será a relação entre coloração e fragmentação. A justificação mais verosímil advém do facto desta última constituir uma resposta óssea à desidratação experimentada durante a combustão. A desidratação que, aliás, é a primeira reacção óssea ao calor, não exige temperaturas altas para se manifestar bastando 100 a 600 ${ }^{\circ} \mathrm{C}$ (Thompson, 2004) o que pode explicar para a nossa amostra os valores de fissuras exibidos pelas peças ósseas de coloração amarela.

Por fim, a análise dos valores relativos às quatro características físicas, por tipo de osso, aponta para a inexistência de diferenças assinaláveis na exposição dos distintos elementos do esqueleto ao foco de calor, aspecto que sugere a hipótese duma combustão simultânea dos restos humanos no local onde haviam sido depositados, isto é, uma cremação múltipla ${ }^{7}$.

Embora sucinta, a interpretação dos dados obtidos para as restantes marcas tafonómicas não atribuíveis ao fogo permite ter acesso a informação relevante sobre o ambiente que circundava os restos ósseos, dando, igualmente, azo a que se descodifiquem alguns gestos humanos a que terão sido submetidos. Dentro do primeiro grupo, ainda que motivados por diferentes agentes, inserem-se as pintas pretas, os pequenos orifícios, as depressões, os bolores e/ou as pequenas excrescências indeterminadas, enquanto que no segundo estão incluídas as fracturas recentes e as manchas verdes. No caso das pintas pretas existem duas versões explicativas distintas para este fenómeno. Botella e colaboradores (2000) são da opinião que denunciam microrganismos, nomeadamente colónias de fungos, já autores como Shahack-Gross (1997) ou White (2000) defendem que a cor preta pode ser motivada pelo manganês. Para a origem dos orifícios, as evidências sugerem a acção de insectos (Andrews, 1995) e/ou de artrópodes (Pitarch et al., 1999). Bem mais dúbia é a justificação para as pequenas excrescências, de cor semelhante ao osso e formato arredondado, patentes na superfície de algumas peças. A única pista encontrada remete-nos para os intrigantes clinkers/escória mencionados por Wells (1960) ou Henderson et al. (1987), facto que só poderá ser averiguado mediante análises histológicas e/ou quí-

${ }^{7}$ Ver Silva (2007). 
micas. Actualmente existem duas hipóteses explicativas para este material: Hummel et al. 1988 in Grévin, 1990) consideram tratar-se de resíduos provenientes da fusão de cinzas, sobretudo de origem óssea, enquanto Henderson et al. (1987) afirmam serem devidos a sílica de solos arenosos fundida com materiais da pira funerária a temperaturas elevadas.

Quanto às modificações que, directa ou indirectamente, reflectem a intervenção humana, teceremos algumas considerações relativas às manchas verdes. Estas são consequência da presença de metais no ambiente circundante, nomeadamente, cobre (Buikstra e Ubelaker, 1994; Botella et al., 2000). Tal suposição parece não se coadunar com a natureza do vasto espólio arqueológico encontrado em OP2b (artefactos votivos e elementos de adorno pessoal), o qual apenas integra um punhal em cobre (Gonçalves, 1999). Este autor refere, inclusive, que o cobre constitui um metal raríssimo nas antas de Reguengos de Monsaraz.

\section{Inferências de âmbito paleodemográfico e paleopatológico}

A pesquisa de dados de natureza paleodemográfica e paleopatológica esteve alicerçada na convicção de que as características físicas dos elementos ósseos não deveriam servir de desculpa para que esta análise fosse descurada, mesmo sabendo, a priori, das inerentes limitações a que iria estar sujeita. É de crer que quaisquer informações que permitam ter uma ideia do número mínimo de indivíduos depositados no tholos OP2b, respectiva idade à morte ou sexo possam constituir uma mais-valia para os conhecimentos antropológicos adquiridos sobre os sujeitos inumados neste monumento megalítico.

Em material ósseo cremado, o leque de métodos passíveis de ser utilizado é bastante restrito. Uma apreciação global dos resultados obtidos denuncia, antes de mais, o impacto negativo da elevada fragmentação dos elementos ósseos. Tal circunstância não surpreende uma vez que o teor das informações de índole demográfica e patológica adquiridas através do exame de restos ósseos cremados, está dependente do grau de fragmentação destes e do nível de recolha óssea (McKinley, 2000).

Comparativamente com o N.M.I. auferido para outras sepulturas colectivas onde o fogo também se terá manifestado, constata-se que os indícios da presença de 16 sujeitos na amostra estudada ultrapassam os onze identificados por Lohrke et al. (2002) na sepultura monumental neolítica da Peña 
de la Abuela ou os 13 indivíduos da sepultura I (al-Sufuh, Dubai), datada entre 2400 a 2300 a.C. (Benton, 1996 in Blau, 2001b; Blau, 1998 in Blau, 2001b). O valor encontrado mostra-se, aliás, semelhante ao dos 18 sujeitos revelados no estudo de material osteológico recuperado na escavação de dois metros quadrados da Grotte du Gardon, Neolítico final/recente (Gatto e Buquet, 2000) e ao dos 19 detectados por Castro e Etxeberria (2002) no sepulcro megalítico "El Miradero", em Valladolid.

Em termos paleodemográficos os resultados alcançados enquadram-se no perfil do Neolítico final/Calcolítico traçado por Silva (2002). A proporção de adultos versus não adultos, isto é, nove adultos e sete não adultos (ou $43,75 \%$ ), afigura-se um pouco superior aos $30 \%$ ou $33,7 \%$ de não adultos apresentados por Silva em trabalhos de 1996 e 2002, respectivamente. $\mathrm{Na}$ realidade, os valores que mais se aproximam dos da presente amostra são provenientes da estação de São Paulo com 48,4\%, seguido dos do Dólmen de Ansião com 37,8\% (Silva, 2002). Noutras sepulturas colectivas europeias, alvo da acção do fogo, o cenário mantém-se. Gatto e Buquet (2000) obtiveram 38,89\% de não adultos na Grotte du Gardon do Neolítico final/ recente enquanto Chambon (1999) registou $28,57 \%$ na sepultura neolítica de Neuvy-en-Dunois, em Eure-et-Loir. Já Lohrke et al. (2002) apresentaram 18,19\% para a sepultura monumental neolítica da Peña de la Abuela e Castro e Etxeberria (2002) mencionam somente 10,53\% para o sepulcro megalítico "El Miradero".

No que respeita à estimativa da idade à morte, estão representados todos os grupos etários considerados, crianças (entre os 0 a 4 anos), passando por adolescentes (10 a 14/15 anos), até adultos idosos, facto igualmente mencionado por Silva (2002). Outro aspecto que espelha os dados desta autora consiste na distribuição dos indivíduos não adultos pelos grupos etários considerados, mais concretamente, a propensão para a diminuição na frequência de N. M. I. à medida que a idade avança.

Muito embora o tamanho da amostra impeça um retrato fidedigno da população, todos os métodos aplicados sugerem haver um número maior de indivíduos do sexo feminino em relação ao masculino (4:2). Segundo documenta Silva (2002) a tendência para o predomínio de mulheres é usual em séries portuguesas coevas. Na óptica da autora, tal desproporção é susceptível de reflectir a existência real de um número mais elevado de mulheres nessas populações portuguesas pré-históricas (hipótese que considera mais plausível), resultar de práticas funerárias distintas (como seja a inumação 
de indivíduos masculinos com diferentes estatutos sociais noutro local) ou advir dos próprios métodos empregues na diagnose sexual.

Apesar dos muitos obstáculos inerentes ao estudo de restos osteológicos cremados, o diagnóstico de patologias continua a ser viável (Reverte, 1991; Reinhard e Fink, 1994; Bellard, 1996) ainda que nem sempre estejam reunidas as condições necessárias para um diagnóstico diferencial. No domínio da patologia degenerativa foram detectados casos de artrose e de entesopatias. Por norma, as lesões degenerativas do tipo artrose têm uma boa resistência à cremação sendo, por isso, facilmente observáveis (Depierre, 1995). Quanto aos resultados obtidos, indicam, à semelhança do encontrado por Silva (2002), uma baixa incidência de artrose nesta amostra. No que toca às articulações mais afectadas, nomeadamente, do cotovelo, da mão e do joelho (no esqueleto apendicular) e as da coluna vertebral não é possível traçar analogias. Importa estar ciente que outras articulações poderiam estar lesionadas ainda que não se tenham preservado. Relativamente às entesopatias, inseridas no campo da patologia degenerativa não articular, as lesões mais frequentes respeitam à região de inserção do biceps brachii, do ligamento rotuliano e do ligamento flexor das falanges proximais. Segundo Stone e Stone (1997), a lesão na tuberosidade biccipital está relacionada com a flexão do antebraço. Já as entesopatias dos ligamentos flexores das falanges serão motivadas por factores de stresse, como seja a flexão dos dedos quando se segura firmemente uma ferramenta ou instrumento (Capasso et al., 1999).

As demais lesões observadas constituem casos isolados sem significado a nível populacional. Neste grupo situa-se o nódulo de Schmorl considerado por alguns autores como de etiologia desconhecida (Saluja et al., 1986 in Roberts e Manchester, 1995) ou como um problema de crescimento decorrente de pressões mecânicas que levam à formação de hérnias no disco intervertebral (Cunha, 1994). A localização mais frequente ocorre nas vértebras torácicas inferiores e lombares (Saluja et al., 1986 in Roberts e Manchester, 1995), o que se verifica também no presente estudo. Evidências de nódulos de Schmorl foram, de igual modo, assinaladas por Blau (2001a) em material ósseo cremado proveniente de sepulturas colectivas datadas do terceiro milénio; a espessura do diploe em vários fragmentos cranianos, fenómeno igualmente registado por Malgosa e colaboradores (1995) em materiais cremados da Necrópole de "El Poblado" e para os quais os autores também não chegaram a um diagnóstico seguro; um caso de espinha bífida, um problema congénito comum, de acordo com Ortner (2003); e um 
rádio com lesões atribuíveis a um distúrbio metabólico, não inflamatório, benigno designado por osteocondritis dissecans, o qual se caracteriza pela produção de pequenas áreas de necrose nas diartroses resultante na perda de um segmento de osso subcondral (Aufderheide e Rodríguez-Martín, 1998). Esta patologia foi encontrada por Silva $(2002 ; 2003)$ em diversos ossos, que não o rádio, dos sítios de Paimogo e de Serra da Roupa.

Conquanto a detecção de patologia traumática, nomeadamente de indícios de fracturas in vitam, seja uma tarefa complicada, pelo facto da acção do fogo afectar precisamente a linha da ruptura (Bellard, 1996), saliente-se a identificação de uma num $3^{\circ}$ metacárpico esquerdo, com a particularidade, segundo Roberts e Manchester (1995), dos ossos das mãos serem pouco afectados por este tipo de patologia. Por último, de mencionar vestígios de processos infecciosos, em dois fragmentos de costela e num de fémur, cuja natureza monótona da reacção do periósteo e as características da amostra apenas permite afirmar tratar-se de um sinal de etiologia inespecífica.

Em suma, o presente trabalho revela que em material ósseo cremado, ainda que as características físicas, nomeadamente, a fragmentação e a deformação, suscitem dificuldades acrescidas no campo da identificação, e possam comprometer a aplicação de certos métodos na esfera da paleodemografia e da paleopatologia, continua a ser viável obter informações de âmbito antropológico, dados vitais para o conhecimento dos nossos antepassados.

\section{Agradecimentos}

À Ana Luísa Santos agradecemos toda a motivação e apoio dados. Estamos igualmente gratos aos revisores científicos e ao conselho editorial pelas sugestões apresentadas.

\section{Bibliografia}

Andrews, P. 1995. Experiments in taphonomy. Journal of Archaeological Science, 22: $147-153$.

Alduc-Le Bagousse, A. 1988. Estimation de l'âge des non-adultes, maturation dentaire et croissance osseuse. Données comparatives pour deux populations médiévales bas-normande. Actes des 3èmes Journées Anthropologiques. Notes et Monographies Tecnhiques, 24. Paris, Editions du CNRS: 81-103. 
Aufderheide, A.; Rodríguez-Martín, C. 1998. The Cambridge encyclopedia of human paleopathology. Cambridge, Cambridge University Press.

Bass, W. 1995. Human osteology: a laboratory and field manual. $4^{\text {th }}$ Edition. Columbia, Missouri Archeological Society.

Bellard, F. 1996. El análisis antropológico de las cremaciones. Complutum Extra, 6(2): 55-64.

Benito, J. 2002. Incineración y cremación parcial en contextos funerarios neolíticos y calcolíticos del este peninsular al sur del Xúquer. In: Rojo, M.; Kunst, M. (eds.). Sobre el significado del fuego en los rituales del Neolítico. Studia Archaeologica, 91: 155-190.

Blau, S. 2001a. Limited yet informative: pathological alterations observed on human skeletal remains from third and second millennia BC collective burials in the United Arab Emirates. International Journal of Osteoarchaeology, 11: 173-205.

Blau, S. 2001b. Fragmentary endings: a discussion of $3^{\text {rd }}$ millennium BC burial practices in the Oman Peninsula. Antiquity, 75: 557-70.

Boddington, A. 1987. Chaos, disturbance and decay in an Anglo-saxon cemetery. In: Boddington, A.; Garland, A.; Janaway, R. (eds.). Death, decay and reconstruction: approaches to archaeology and forensic science. Manchester, Manchester University Press: 27-42.

Botella, M.; Alemán, I.; Jiménez, S. 2000. Los huesos humanos: manipulación y alteraciones. Barcelona, Edicions Bellaterra.

Brooks, S.; Suchey, J. 1990. Skeletal age determination based on the os pubis: a comparison of the Acsádi-Neméskeri and Suchey Brooks methods. Human Evolution, 5(3): 227-238.

Buikstra, J.; Ubelaker, D. 1994. Standards for data collection from human skeletal remains: Proceedings of a seminar at the Field Museum of Natural History. Fayetteville, Arkansas (Arkansas Archaeological survey research series; 44).

Capasso, L.; Kennedy, K.; Wilczak, C. 1999. Atlas of occupational markers on human remains. Teramo, Edigrafital S.P.A.

Castro, G.; Etxeberria, F. 2002. Fuego y cal en el sepulcro colectivo de "El Miradero" (Valladolid): accidente, ritual o burocracia de la muerte? In: Rojo, M.; Kunst, M. (eds.). Sobre el significado del fuego en los rituales del Neolítico. Studia Archaeologica, 91: 39-58.

Chambon, P. 1999. Du cadavre aux ossements: la gestion des sépultures collectives dans la France néolithique. Thèse de doctorat. Paris, Université de Paris I. 
Correia, P. 1997. Fire modification of bone: a review of the literature. In: Haglund,

W.; Sorg, M. (eds.). Forensic Taphonomy: the post-mortem fate of human remains. New York, CRC Press: 275-293.

Crubézy, E. 1988. Interactions entre facteurs bio-culturels, pathologie et caractères discrets: exemple d'une population médiévale, Canac, Aveyron. Thèse de doctorat en Médicine. Montpellier, Université de Montpellier.

Cunha, E. 1994. Paleobiologia das populações medievais portuguesas - os casos de Fão e S. João da Almedina. Dissertação de Doutoramento em Antropologia Biológica, Departamento de Antropologia, Universidade de Coimbra.

Darwent, C.; Lyman, R. 2002. Detecting the postburial fragmentation of carpals, tarsals, and phalanges. In: Haglund, W.; Sorg, M. (eds.). Advances in forensic taphonomy: method, theory, and archaeological perspectives. London, CRC Press: $355-378$.

Depierre, G. 1995. Les pratiques funéraires gallo-romaines, liées à l'incinération: apports spécifiques de l'ostéologie, de l'archéologie et de l'ethnologie. Diplôme d'Études Approfondies. Bordeaux, Université de Bordeaux.

Eckert, W.; James, S.; Katchis, S. 1988. Investigation of cremations and severely burned bodies. The American Journal of Forensic Medicine and Pathology, 9(3): 188-200.

Etxeberria, F. 1994. Aspectos macroscópicos del hueso sometido al fuego. Revisión de las cremaciones descritas en el País Vasco desde la Arqueología. Munibe, 46: 111-116.

Ferreira, M. 2000. As crianças moçárabes de Serpa: análise paleobiológica de uma amostra de esqueletos exumados da necrópole do loteamento da Zona Poente de Serpa. Relatório de Investigação, Departamento de Antropologia, Universidade de Coimbra.

Ferembach, D.; Schwidetzky, I.; Stloukal, M. 1977-1979. Raccomandazioni per la determinazione dell'età e del sesso sullo scheletro. Rivista di Antropologia, LX: 5-51.

Galloway, A.; Willey, P.; Snyder, L. 1997. Human bone mineral densities and survival of bone elements: a contemporary sample. In: Haglund, W.; Sorg, M. (eds.). Forensic taphonomy: the post-mortem fate of human remains. New York, CRC Press: 295-317.

Gatto, E.; Buquet, C. 2000. La structure plurielle à crémations de la Grotte du Gardon (Ain): une pratique funéraire originale du Néolithique Récent? Bulletins et Mémoires de la Société d'Anthropologie de Paris, 12(3-4): 303-332. 
Gatto, E.; Basset, G.; Méry, S.; Mc Sweeney, K. 2003. Étude paléodémographique et utilisation du feu à Hili N., une sépulture collective en fosse de la fin de l'Âge du Bronze Ancien aux Émirats Arabes Unis. Bulletins et Mémoires de la Société d'Anthropologie de Paris, 15(1-2): 25-47.

Gonçalves, V. 1992. Revendo as Antas de Reguengos de Monsaraz. Cadernos da UNIARQ. Lisboa, Instituto Nacional de Investigação Científica.

Gonçalves, V. 1999. Reguengos de Monsaraz: territórios megalíticos. Lisboa, VSG e MNA.

Gonçalves, V.; Sousa, A. C. 1997. A propósito do grupo megalítico de Reguengos de Monsaraz e das origens do megalitismo no Ocidente Peninsular. In: Casal, A. (ed.). O Neolítico Atlántico e as Orixes do Megalitismo. Santiago de Compostela, Universidade de Santiago de Compostela: 609-634.

Gonçalves, V.; Sousa, A. C. 2000. O grupo megalítico de Reguengos de Monsaraz e a evolução do megalitismo no Ocidente Peninsular (espaços de vida, espaços da morte: sobre as antigas sociedades camponesas em Reguengos de Monsaraz). In: Gonçalves, V. (ed.). Muitas antas, pouca gente? Actas do I Colóquio Internacional sobre Megalitismo. Lisboa, Instituto Português de Arqueologia: 11-104.

Grévin, G. 1990. La fouille en laboratoire des sépultures à incinération, son apport à l'archéologie. Bulletins et Mémoires de la Société d'Anthropologie de Paris, 2(3-4): 67-74.

Grévin, G.; Bailet, P.; Quatrehomme, G. ; Ollier, A. 1998. Anatomical reconstruction of fragments of burned human bones: a necessary means for forensic identification. Forensic Science International, 96(2-3): 129-134.

Guillon, F. 1987. Brûlés frais ou brûlés secs? In: Duday, H. ; Masset, C. (eds.). Anthropologie physique et archéologie: méthodes d'étude des sépultures. Actes du Colloque de Toulouse, 4-6 Novembre 1982. Paris, Éditions CNRS: 191-194.

Hauser, G.; De Stefano, G. 1989. Epigenetic variation of the human skull. Stuttgart, Schweizerbart.

Heglar, R. 1984. Burned remains. In: Rathbun, T.; Buikstra, J. (eds.). Human identification: case studies in forensic anthropology. Springfield, Charles C. Thomas: 148-158.

Henderson, J.; Janaway, R.; Richards, R. 1987. Cremation slag: a substance found in funerary urns. In: Boddington, A.; Garland, A.; Janaway, R. (eds.). Death, decay and reconstruction: approaches to archaeology and forensic science. Manchester, Manchester University Press: 81-100. 
Herrmann, N.; Bennett, J. 1999. The differentiation of traumatic and heat-related fractures in burned bone. Journal of Forensic Sciences, 44(3): 461-469.

Herrmann, B.; Grupe, G.; Hummel, S.; Piepenbrink, H.; Schutkowski, H. 1990. Praehistorische Anthropologie. Leitfaden der Fels-und Labormethoden. Berlin, Springer Verlag.

Lohrke, B.; Wiedmann, B.; Alt., K. 2002. Die anthropologische skelettreste aus La Peña de la Abuela, Ambrona (Prov. Soria). In: Rojo, M.; Kunst, M. (eds.). Sobre el significado del fuego en los rituales del Neolítico. Studia Archaeologica, 91: 83-98.

Lovejoy, C.; Meindl, R.; Pryzbeck, T.; Mensforth, R. 1985. Chronological metamorphosis of the auricular surface of the ilium: a new method for the adult skeletal age at death. American Journal of Physical Anthropology, 68: 15-28

Malgosa, A.; Subira, M.; Castellana, C. 1995. Pathological evidences about iberic cremations: necropolis of "El Poblado" (Múrcia; Spain). In: Proceedings of the IXth European Meeting of the Paleopathology Association, $1^{\text {st }}-4^{\text {th }}$ September, 1992, Barcelona. Barcelona, Museu d'Arqueologia de Catalunya: 213-220.

Masset, C. 1982. Estimation de l'âge au décès par les sutures crâniennes. Thèse de Doctorat, Laboratoire d'Anthropologie Biologique. Paris, Université de Paris VII.

Masset, C. 2002. Ce qu'on sait, ou croit savoir, du rôle du feu dans les sépultures collectives néolithiques. In: Rojo, M; Kunst, M. (eds.). Sobre el significado del fuego en los rituales del Neolítico. Studia Archaeologica, 91: 9-20.

Mays, S. 1998. The archaeology of human bones. London, Routledge.

Mckinley, J. 1994. Bone fragment size in British cremation burials and its implications for pyre technology and ritual. Journal of Archaeological Science, 21: 339-342.

Mckinley, J. 2000. The analysis of cremated bone. In: Cox, M.; Mays, S. (eds.). Human osteology in archaeology and forensic science. London, Greenwich Medical Media: 403-421.

Mckinley, J.; Bond J. 2001. Cremated bone. In: Brothwell, D.; Pollard, A. (eds.). Handbook of archaeological sciences. Chichester, John Wiley \& Sons, Ltd.: 281-292.

Ortner, D. 2003. Identification of pathological conditions in human skeletal remains. $2^{\text {nd }}$ Edition.London, Academic Press.

Pajot, B. 1986. Le rite de l'incinération sur la necropole du Frau de Cazals (Tarnet-Garonne). In: Duday, H. ; Masset, C. (dir.). Anthropologie physique et 
archeologie: méthodes d'étude des sépultures. Actes du Colloque de Toulouse 4, 5 et 6 novembre 1982. Paris, Editions CNRS: 379-388.

Phenice, T. 1969. A newly developed visual method of sexing in the os pubis. American Journal of Physical Anthropology, 30: 297-301.

Pitarch, P.; Feucht, M.; Munõz, M.; Cerda, M.; Blanco, J. 1999. Pseudopatologia tafonómica en restos óseos arqueológicos. Actas del Congreso Nacional de Paleopatología. Alcalá la Real, 29 de Abril-2 de Mayo de 1999 [Acedido em 12-03-2005]. http://www.ucm.es/info/aep/boletin/actas

Reinhard, K.; Fink, T. 1994. Cremation in the Southwestern North America: aspects of taphonomy that affect pathological analysis. Journal of Archaeological Science, 21: 597-605.

Reverte, J. 1991. Antropología forense. Madrid, Ministerio de Justiça (Secretaria General Tecnica, Centro de Publicações).

Roberts, C.; Manchester, K. 1995. The archaeology of disease. $2^{\text {nd }}$ Edition. Ithaca, New York, Alan Sutton Publishing Limited.

Rubini, M.; Andreini, L. 1990. Studio di resti scheletrici incinerati scoperti in uno dolio funerario risalente ad Epoca Imperiale Romana rinvenuto in prossimità di Ciampino (Roma, Lazio). Rivista di Antropologia, 68: 267-277.

Saunders, S. 1978. The development and distribution of discontinous morphological variation of human infracranial skeleton. Ottawa, National Museums of Canada, Mercury Series, 81.

Shahack-Gross, R.; Bar-Yosef, O.; Weiner, S. 1997. Black-coloured bones in Hayonim Cave, Israel: differentiating between burning and oxide staining. Journal of Archaeological Science, 24: 439-446.

Silva, A. M. 1996. O Hipogeu de Monte Canelas I (IV-III milénios a. C.): estudo paleobiológico da população humana exumada. Trabalho de síntese. Provas de Aptidão Pedagógica e Capacidade Científica, Departamento de Antropologia, Universidade de Coimbra.

Silva, A. M. 2002. Antropologia Funerária e Paleobiologia das populações portuguesas (litorais) do Neolítico final/Calcolítico. Dissertação de Doutoramento em Antropologia Biológica, Departamento de Antropologia, Universidade de Coimbra.

Silva, A. M. 2003. Evidence of osteochronditis dissecans in Late Neolithic/Chalcolithic Portuguese Populations. In: Campo-Martín, M.; Rodríguez, F. (eds.). Dónde Estamos? Pasado, Presente y futuro de la Paleopatología. Actas del VI Congreso Nacional de Paleopatología (Madrid, 13 al 16 Septiembre de 2001): 464-468. 
Silva, F. C. 2005. Sinais de Fogo: Análise antropológica de restos ósseos cremados do Neolítico fina/Calcolítico do tholos OP2b (Olival da Pega, Reguengos de Monsaraz). Dissertação de Mestrado em Evolução Humana, Departamento de Antropologia, Universidade de Coimbra.

Silva, F. C. 2007. Abordagem ao ritual da cremação através da análise dos restos ósseos. Al-Madan, (II série) 15: 40-48.

Symes, S.; Pope, E.; Smith, O.; Gardner, C.; Zephro, L. 2001. Burning observations III: analysis of fracture patterns in burned human remains. Proceedings of the American Academy of Forensic Sciences, 7: 278.

Sousa, A. C. 2004. Comunicação pessoal.

Spence, T. 1967. The anatomical study of cremated fragments from archeological sites. Proceedings of the Prehistoric Society, 63: 129-145.

Stiner, M.; Kuhn, S.; Weiner, S.; Bar-Yosef, O. 1995. Differential burning, recrystallization, and fragmentation of archaeological bone. Journal of Archaeological Science, 22: 223-237.

Stojanowski, C.; Seidemann, R.; Doran, G. 2002. Differential skeletal preservation at Windover Pond: causes and consequences. American Journal of Physical Anthropology, 119: 15-26.

Stone, R.; Stone, J. 1997. Atlas of skeletal muscles. $2^{\text {nd }}$ Edition. London, Wm. C. Brow Publishers.

Thompson, T. 2004. Recent advances in the study of burned bone and their implications for forensic anthropology. Forensic Science International, 146 supplement 1: S203-S205.

Thurman, M.; Willmore, L. 1980-1981. A replicative cremation experiment. North American Archeologist, 2(4): 275-283.

Toussaint, M. 1991. Étude spatialle et taphonomique de deux sépultures collectives du Néolithique Récent: l'Abri Masson et la Fissure Jacques à Sprimont, province de Liège, Belgique. L'Anthropologie (Paris), 95(1): 257-278.

Ubelaker, D. 1974. Reconstruction of demographic profiles from ossuary skeletal samples: a case from Tidewater Potomac. Smithsonian Contributions to Anthropology 18. Washington D.C.

Ubelaker, D. 1989. Human skeletal remains. $2^{\text {nd }}$ Edition. Washington, Taraxacun. Vázquez, J.; González, T.; Pereira, S. 2002. El fuego en el ritual funerario Bimbape: la necrópolis de Montaña La Lajura (El Hierro, Canarias). In: Rojo, M.; Kunst, M. (eds.). Sobre el significado del fuego en los rituales del Neolítico. Studia Archaeologica, 91: 219-232. 
Wahl, J. 1996. Erfahrungen zur metrischen Geschlechtsdiagnose bei Leichenbranden. Homo, 47(1-3): 339-359.

Wahl, J.; Graw, M. 2001. Metric sex differentiation of the pars petrosa ossis temporalis. International Journal of Legal Medicine, 114: 215-223.

Waldron, T. 1987. The relative survival of the human skeleton: implications for paleopathology. In: Boddington, A.; Garland, A.; Janaway, R. (eds.). Death, decay and reconstruction: approaches to archaeology and forensic science. Manchester, Manchester University Press: 55-64.

Wells, C. 1960. A study of cremation. Antiquity, 34: 29-37.

White, T. 2000. Human osteology. $2^{\text {nd }}$ Edition. San Diego, Academic Press.

Artigo recebido a 3 de Novembro de 2008 e aceite a 6 de Janeiro de 2009. 